\title{
PREDICTORS OF THE NARROWEST PELVIC CAVITY DIAMETER IN LIVE FEMALES AND MALES
}

\author{
Oksana Kolesova, Jānis Vētra \\ Institute of Anatomy and Anthropology, Riga Stradins University, Latvia
}

\begin{abstract}
The aim of this study was to specify the predictors of the narrowest pelvic diameter in females and males. Possible common tendencies and sexual dimorphism in this prediction are in question for measures in live humans. In addition, the relationship between the false pelvis and the true pelvis was not explored in males. The research sample included 211 females and 181 males, who underwent the computer tomography examination in the Hospital Gailezers, Latvia. Three-dimensional pelvic images were used for 12 linear measurements ( 8 diameters of the pelvic cavity in four pelvic levels, conjugata diagonalis, and 3 diameters of the false pelvis). The results demonstrated that the most powerful predictors of the bispinous diameter are the transverse diameter of the inlet and the bituberous diameter. These predictors are significant for both sexes. Sexual dimorphism manifests itself in a greater number of predictors and higher variance explained by these predictors in females. There is no statistical evidence for an accurate prediction of the bispinous diameter based on the diameters of the false pelvis.
\end{abstract}

Keywords: bispinous diameter, CT pelvimetry

\section{INTRODUCTION}

The true pelvis has sexual dimorphism that reflects the evolutionary selection pressure on the pelvic cavity in females $[8,16]$. The shape of the true pelvis is more triangular and deeper in males and more cylindrical and shorter in females [2]. At the same time, the distance between two ischial spines (bispinous diameter) 
is the narrowest place of the pelvic cavity for both sexes [16; 18]. This diameter is highly significant from a clinical perspective. On the one hand, various studies demonstrated that the narrow bispinous diameter and the narrow diameters of the outlet increase the risk of prolonged labor and emergence cesarean section $[3,7,12,21]$. On the other hand, the wider bispinous diameter increases the risk of the pelvic floor disorders in females $[14,19]$. In males, a narrow pelvic cavity increases the risk of complications during and after pelvic organs surgery: prostatectomy $[4,9]$ and rectal cancer resection $[1,11]$. The aim of this study was to specify the predictors of the bispinous diameter in both sexes.

The false pelvis and the true pelvis form a common anatomical structure. It can be expected that the relationship between their parameters can be closer than the relationship with other anthropometric measures and the true pelvis, but the previous studies revealed a relatively low level of correlations between some diameters of the false and the true pelvis in females $[10,20]$. The relationships of these dimensions in males are not presented in literature. In addition, the most part of the studies on the relationships among parameters was performed on skeletal collections without taking into account pelvic joints $[5,6,10,17]$. Therefore, this study focuses on two aspects of the prediction of the bispinous diameter: 1) the relationship between the false pelvis and the true pelvis, which is not explored in males; 2 ) the sexual dimorphism in this prediction, which seems to be topical for measures in live humans.

\section{MATERIAL AND METHODS}

The pelvimetry was performed on the archive data of the Department of Radiology, Hospital Gailezers, Latvia, in the period from October 2009 to November 2010. The archive data were available according to legal requirements.

The research sample included 211 females aged from 18 to 84 (the mean age $=48.3, \mathrm{SD}=18.3$ years) and 181 males aged from 18 to 82 (the mean age $=43.6$, $\mathrm{SD}=16.1$, who underwent the computer tomography (CT) examination due to abdominal pain and abdominal inflammatory processes. Exclusion criteria were the bones' fractures, transitional vertebras, scoliosis, osteoporosis, and polytrauma. The number of participants provided an acceptable ratio of cases to independent variables suggested for a multiple linear regression [15].

CT was performed by 64-slice scanner (General Electric Medical Systems Light Speed) with scanning parameters established at $120 \mathrm{kV}, 150-500 \mathrm{~mA}$ 
with slice thickness at $1.25 \mathrm{~mm}$ and the pelvimetry was performed on the threedimensional workstation using multiplanar reconstruction and volume-rendered images. The superior-anterior, right lateral and posterior pelvic views were used for 12 linear measurements. All the measures were obtained by one investigator. Assessed in a subsample of 23 participants, the intra-rater reliability varied from .92 to .99 .

The transverse diameters were: 1 ) the transverse diameter of the inlet - the widest distance between iliopectineal lines; 2) the biacetabular diameter - the distance between the middle of acetabulums; 3 ) the bispinous diameter - the narrowest distance between two ischial spines; 4) the bituberous diameter (the transverse diameter of the outlet) - the widest distance betweenthe inner margins of the ischial tuberosities; 5) Distantia intercristalis - the widest distance between iliac crests; 6) Distantia interspinosa - the widest distance between anterior superior iliac spines; 7) Distantia intertrochanterica - the widest distance between greater trochanters.

The sagittal diameters were: 8 ) the sagittal diameter of the inlet - the distance between the superior border of the pubic symphysis and the promontory of the sacrum; 9) the sagittal diameter S2-S3 - the distance between the posterior midpoint of pubic symphysis and the anterior point between the second and the third sacral vertebrae; 10) the sagittal diameter S4-S5 - the distance between the lower border of pubic symphysis and the anterior point between the fourth and the fifth sacral vertebrae; 11) the sagittal diameter of the outlet - the distance between lower border of pubic symphysis and the apex of the coccyx; 12) Conjugata diagonalis - the distance between the inferior border of the pubic symphysis and the promontory of the sacrum.

The statistical analysis was performed through a multiple linear regression procedure. A two-step multiple regression was performed in order to evaluate an amount of variance explained by the parameters of the false pelvis and the true pelvis.

\section{RESULTS}

A two-step multiple linear regression was performed separately on the data of the female sample and of the male sample. The first step included the bispinous diameter as a dependent variable and distantia intercristalis, distantia interspinosa, and distantia intertrochanterica as independent variables. At the second step, 
the true pelvis diameters were added to the regression model as independent variables.

In the female sample (Table 1), Step 1 demonstrated that distantia intercristalis and distantia interspinosa do not predict the bispinous diameter. At the same time, distantia intertrochanterica is a predictor of the bispinous diameter. Step 2 demonstrated significant changes in the model. The importance of distantia intertrochanterica decreased when the bituberous diameter, the transverse diameter of the inlet, and the sagittal diameter of the outlet added $43 \%$ to explained variance. In sum, the model explained $69 \%$ of the variance of the bispinous diameter.

Table 1. Two-step multiple linear regression of the bispinous diameter in females $(n=211)$.

\begin{tabular}{|c|c|c|c|c|}
\hline Independent variables & B & SE B & $\beta$ & $t$ \\
\hline \multicolumn{5}{|c|}{ Step 1: $F(3,208)=23.95, p<.001, R^{2}=.26$} \\
\hline Distantia intercristalis & -0.13 & 0.07 & -.24 & 1.85 \\
\hline Distantia interspinosa & -0.01 & 0.05 & -.02 & -0.16 \\
\hline Distantia intertrochanterica & 0.42 & 0.06 & .66 & $7.69^{\star \star \star}$ \\
\hline \multicolumn{5}{|c|}{$\begin{array}{l}\text { Step 2: } F(11,200)=38.99, p<.001, R^{2}=.69 \\
\Delta R^{2}=.43, p<.001\end{array}$} \\
\hline Distantia intercristalis & -0.05 & 0.05 & -.08 & -0.96 \\
\hline Distantia interspinosa & -0.06 & 0.04 & -.13 & -1.66 \\
\hline Distantia intertrochanterica & 0.12 & 0.04 & .18 & $2.71^{* *}$ \\
\hline Transverse inlet & 0.29 & 0.08 & .26 & $3.41^{* \star *}$ \\
\hline Biacetabular diameter & 0.13 & 0.08 & .12 & 1.57 \\
\hline Bituberous diameter & 0.48 & 0.05 & .52 & $9.74^{\star \star \star}$ \\
\hline Sagittal inlet & 0.04 & 0.12 & .04 & 0.30 \\
\hline Sagittal S2-S3 & -0.09 & 0.05 & -.10 & -1.69 \\
\hline Sagittal S4-S5 & 0.06 & 0.07 & .05 & 0.88 \\
\hline Sagittal outlet & 0.11 & 0.05 & .12 & $2.16^{*}$ \\
\hline Conjugata diagonalis & -0.10 & 0.11 & -.11 & -0.91 \\
\hline
\end{tabular}

${ }^{*} \mathrm{p}<.05 ;{ }^{* *} \mathrm{p}<.01 ;{ }^{* * *} \mathrm{p}<.001$

In the male sample (Table 2), Step 1 revealed similar tendencies among independent variables. Only distantia intertrochanterica predicted the bispinous diameter. However, an amount of variance explained by this step is lower than in females. Step 2 confirmed the low level of relationships among the variables 
included in the model at Step 1. The bituberous diameter and the transverse diameter of the inlet predicted the bispinous diameter significantly while distantia intertrochanterica was no more a predictor. In sum, the model explained $51 \%$ of variance of the bispinous diameter.

Table 2. Two-step multiple linear regression of the bispinous diameter in males $(n=181)$.

\begin{tabular}{ccccc}
\hline Independent variables & B & SE B & $\boldsymbol{\beta}$ & t \\
\hline Step 1: $\mathrm{F}(3,178)=6.47, \mathrm{p}<.001, \mathrm{R}^{2}=.10$ & & & & \\
\hline Distantia intercristalis & 0.02 & 0.07 & .03 & 0.22 \\
\hline Distantia interspinosa & 0.01 & 0.06 & .01 & 0.04 \\
\hline Distantia intertrochanterica & 0.15 & 0.05 & .30 & $3.23^{* *}$ \\
\hline Step 2: $\mathrm{F}(11,170)=15.52, \mathrm{p}<.001$, & & & & \\
$\mathrm{R}^{2}=.51, \Delta \mathrm{R}^{2}=.41, \mathrm{p}<.001$ & & & & \\
\hline Distantia intercristalis & -0.03 & 0.06 & -.06 & -0.52 \\
\hline Distantia interspinosa & -0.01 & 0.05 & -.02 & -0.23 \\
\hline Distantia intertrochanterica & 0.04 & 0.04 & .09 & 1.10 \\
\hline Transverse inlet & 0.34 & 0.12 & .28 & $2.87^{* *}$ \\
\hline Biacetabular diameter & 0.16 & 0.10 & .14 & 1.55 \\
\hline Bituberous diameter & 0.42 & 0.06 & .45 & $6.99^{\star \star *}$ \\
\hline Sagittal inlet & -0.05 & 0.12 & -.06 & -0.43 \\
\hline Sagittal S2-S3 & -0.05 & 0.07 & -.05 & -0.65 \\
\hline Sagittal S4-S5 & -0.05 & 0.08 & -.05 & -0.62 \\
\hline Sagittal outlet & 0.09 & 0.08 & .08 & 1.10 \\
\hline Conjugata diagonalis & -0.14 & 0.11 & -.18 & -1.30 \\
\hline
\end{tabular}

${ }^{\star \star} p<.01 ;{ }^{* \star \star} p<.001$

\section{DISCUSSION}

The results of this study demonstrated that the most powerful predictors of the narrowest pelvic cavity diameter are the transverse diameter of the inlet and the bituberous diameter. These two diameters predict the bispinous diameter in both sexes. The sagittal diameter of the outlet and distantia intertrochanterica are additional predictors of the narrowest pelvic diameter in females. Distantia intertrochanterica as a characteristic of the body width explained the variation of the bispinous in females while two dimensions of the false pelvis does not explaine the variance of this diameter. In males, only two dimension of the true pelvis explained the variance of the bispinous diameter. It means that 
interrelations between the bispinous diameter and other pelvic parameters in females are closer than in males.

Walrath and Glanz described sexual dimorphism in the predictors of the bispinous diameter and found that the body weight and the femoral head diameter squared are the predictors of the diameter only in females [18], while Tague has not found sexual dimorphism in the described relationship [17]. At the same time, Walrath and Glanz found that the transverse diameter of the inlet is a predictor of the bispinous diameter in both sexes [18]. The present study confirmed sexual dimorphism in the predictors of the narrowest pelvic diameter in the sense of the explained variance and of the number of predictors. Our findings also indicate that two dimensions of the pelvic cavity - the transverse diameter of the inlet and the bituberous diameter - are the most significant predictors for both sexes.

From a clinical perspective, relative independence from the false pelvis emphasizes a need to investigate the pelvic cavity in order to access the risk of possible obstetrical or surgical complications identified in the previous studies $[3,4,9,11,21]$. Distantia intertrochanterica as a characteristic of the body width explains only the limited amount of variance of the narrowest pelvic diameter in females. Therefore, its use as a predictor is also limited.

It should be noted that limited access to patients' data (e.g., pelvic floor disorders, the number of labour, and other anamnestic data) does not allow suggesting of a broader model for the statistical analysis. In addition, possible age-related differences are in question for a further research in a broader group of live humans.

In summary, we have found no statistical evidence for a prediction of the bispinous diameter based on the diameters of the false pelvis. Two transverse diameters of the true pelvis are the most significant predictors of the bispinous diameter in females and males. Revealed sexual dimorphism manifests itself in a greater number of predictors of the bispinous diameter and higher variance explained by these predictors in females.

\section{REFERENCES}

1. Boyle K. M., Petty D., Chalmers A. G., Quirke P., Cairns A., Finan P. J., Sagar P. M., Burke D. (2005). MRI assessment of the bony pelvis may help predict resectability of rectal cancer. Colorectal Dis, 7, 232-240. 
2. Caldwell W. E., Moloy H. C. (1933). Anatomical variation in the female pelvis and their effect in labor with a suggested classification. $58^{\text {th }}$ Annual Meeting of the American Gynecological Society, 479-504.

3. Gowri V., Jain R., Rizvi S. (2010). Magnetic resonance pelvimetry for trial of labour after a previous caesarean section. SQU Med J, 10, 1, 210-214.

4. Hong S. K., Chang I. H., Han B. K., Yu J. H., Han J. H. (2007). Impact of variations in bony pelvic dimensions on performing radical retropubic prostatectomy. Urology, 69, 907-911.

5. Kurki H. K. (2007). Protection of obstetric dimensions in a small-bodied human sample. Am J Physic Anthropol, 133, 1152-1165.

6. Kurki H. K. (2011). Pelvic dimorphism in relation to body size and body size dimorphism in humans. Journal of Human Evolution, 61, 631-643.

7. Lenhard M. S., Johnson T. R. C., Weckback S., Friese K., Hasbargen U. (2010). Pelvimetry revisited: Analyzing cephalopelvic disproportion. European Journal of Radiology, 74, 107-111.

8. Lovejoy C. O. (1988). Evolution of human walking. Sci Am, 259, 118-125.

9. Rabbani F., Herran Yunis L., Vora K., Eastham J. A., Guillonneau B., Scardino P. T., Touijer K. (2009). Impact of ethnicity on surgical margins at radical prostatectomy. BJU Int, 104, 904-908.

10. Ridgeway B., Arias B. E., Barber M. D. (2011). The relationship between anthropometric measurements and the bony pelvis in African American and European American women. Int Urogunecol J, 22, 1019-1024.

11. Salerno S., Daniels I. R., Brown G., Heald R., Moran B. J. (2006). Magnetic resonance imaging pelvimetry in 186 patients with rectal cancer confirms an overlap in pelvic size between males and females. Blackwell Publiching Ltd. Colorectal Diseases, 8, 772-776.

12. Sporri S., Thoeny H. C., Raio L., Lachat R., Vock P., Schneider H. (2002). MR imaging pelvimetry: a useful adjunct in the treatment of women at risk for dystocia? AJR, 179, 1, 137-144.

13. Stalberg K., Bodestedt A., Lyrenas S., Axelsson O. (2006). A narrow pelvic outlet increases the risk for emergency cesarean section. Acta Obstetrica et Gynecologica Scandinavica, 85, 821-824.

14. Sze E. H., Kohli N., Miklos J. R., Roat T., Karram M. M. (1999). Computed tomography comparison of bony pelvis dimensions between women with and without genital prolapse. Obstet Gynecol, 93, 2, 229-232.

15. Tabachnick B. G., Fidell L. S. (2007). Using Multivariate Statistics. $5^{\text {th }}$ ed. Boston (MA): Allyn and Bacon.

16. Tague R. G. (1989). Variation in pelvic size between males and females. Amer J Phys Anthropol, 80, 59-71.

17. Tague R. G. (2000). Do big females have big pelves? Am J Phys Anthropol, 112, 377-393. 
18. Walrath D. E., Glantz M. M. (1996). Sexual dimorphism in the pelvic midplane and its relationship to Neanderthal reproductive patterns. Am J Phys Anthropol, 100, 89-100.

19. Xu H. N., Xia Z. J., Li B. X., Yin Y. T., Wang F., Hu Q. Zhao Y. (2011). Investigation of correlation between diameters of pelvic inlet and outlet planes and female pelvic floor dysfunction. Eur J Obstet Gynecol Reprod Biol, 159, 2, 461-464.

20. Young M., Ince J. G. H. (1940). A radiographic comparison of the male and female pelvis. Journal of Anatomy, 74, 3, 374-385.

21. Zaretsky M. V., Alexander J. M., McIntire D. D., Hatab M. R., Twickler D. M., Leveno K. J. (2005). Magnetic resonance imaging pelvimetry and the prediction of labor dystocia. Obstet Gynecol, 106, 5Pt1, 919-926.

\section{Address for correspondence:}

Oksana Kolesova

Riga Stradiņš University

Institute of Anatomy and Anthropology

16 Dzirciema Street, LV-1007, Riga, Latvia

Postal address: Lacplesa iela, 43/45-10, Riga, LV-1011, Latvia

E-mail: oksana-kolesova@inbox.lv 